Pesq. Vet. Bras. 29(1):71-75, janeiro 2009

\title{
Avaliação in vitro da eficácia de desinfetantes comerciais utilizados no pré e pós-dipping frente amostras de Staphylococcus spp. isoladas de mastite bovina ${ }^{1}$
}

\author{
Elizabeth Sampaio de Medeiros ${ }^{2}$, Marcos Veiga dos Santos ${ }^{4}$, José Wilton \\ Pinheiro Júnior ${ }^{3}$, Eduardo Bento de Faria ${ }^{2}$, Guido Gomes Wanderley ${ }^{5}$ José \\ Andreey Almeida Teles ${ }^{6}$ e Rinaldo Aparecido Mota ${ }^{3^{*}}$
}

\begin{abstract}
Medeiros E.S., Santos M.V., Pinheiro Jr J.W., Faria E.B., Wanderley G.G., Teles J.A.A. \& Mota R.A. 2009. [In vitro evaluation of the efficacy of commercial disinfectants used in pre and post-dipping against Staphylococcus spp. isolated from bovine mastitis.] Avaliação in vitro da eficácia de desinfetantes comerciais utilizados no pré e pós-dipping frente amostras de Staphylococcus spp. isoladas de mastite bovina. Pesquisa Veterinária Brasileira 29(1):71-75. Departamento de Medicina Veterinária, Universidade Federal Rural de Pernambuco, Rua Dom Manoel de Medeiros s/n, Dois Irmãos, Recife, PE 52171-900, Brazil. E-mail: rinaldo.mota@ hotmail.com

The objective of this investigation was to evaluate the in vitro sensibility of Staphylococcus spp. to several commercially available disinfectants used for pre and post dipping. A total of 60 isolates of Staphylococcus spp., identified as Staphylococcus aureus (50) and Positive coagulase Staphylococcus (10) were obtained from the mammary glands of dairy cows with subclinical mastitis in the regions of Metropolitan Recife, the Agreste and the Zona da Mata of the State of Pernambuco, Brazil. As active ingredients were used a chlorine base $(25 \%)$, iodine $(0.6 \%)$, chlorhexidine $(2.0 \%)$, quaternary ammonium (4.0\%), and lactic acid (2.0\%) at four specific intervals (15", 30", 60", and $300 ")$. One hundred percent of $S$. aureus was found to be sensitive to iodine, $93.3 \%$ to chlorhexidine, $80 \%$ to ammonia, $35.6 \%$ to lactic acid, and $97.8 \%$ were resistant to chlorine at a 60-minute interval. With respect to the Positive coagulase Staphylococcus (SCP), $100.0 \%$ of the isolates were sensitive to iodine, $81.8 \%$ to quaternary ammonium, $99.9 \%$ to lactic acid, $72.7 \%$ to chlorhexidine, and $100 \%$ was resistant to chlorine at an interval of 60 minutes. It can be concluded that the highest disinfectant activity in vitro was found to be with iodine and chlorhexidine for S. aureus, and with iodine and lactic acid for SCP. A further conclusion was that it is important to undertake a periodic evaluation of the disinfectants used on the dairy properties in the regions studied, given the variety of sensibilities and resistance to disinfectants used, which may prejudice the control of bovine mastitis caused by Staphylococcus spp.
\end{abstract}

INDEX TERMS: Disinfectants, mastitis, Staphylococcus spp., dairy cows.

\footnotetext{
${ }^{1}$ Recebido em 16 de abril de 2008.

Aceito para publicação em 22 de agosto de 2008.

Trabalho extraído da Dissertação de Mestrado do Programa de Pósgraduação em Ciência Veterinária, Universidade Federal Rural de Pernambuco (UFRPE), Avenida Dom Manoel de Medeiros s/n, Dois Irmãos, Recife, PE 52171-900.

${ }^{2}$ Mestrando em Ciência Veterinária, Departamento de Medicina Veterinária, UFRPE, Recife, PE, Brasil.

${ }^{3}$ Departamento de Medicina Veterinária, UFRPE, Avenida Dom
}

\footnotetext{
Manoel de Medeiros s/n, Dois Irmãos, Recife, PE 52171-900. *Autor para correspondência: rinaldo.mota@ hotmail.com

${ }^{4}$ Departamento de Nutrição e Produção Animal, Universidade de São Paulo (USP), Campus Pirassununga, Av. Duque de Caxias, Pirassununga, SP 58700-970, Brasil.

${ }^{5}$ Graduando em Medicina Veterinária, Departamento de Medicina Veterinária, UFRPE, Recife, PE.

${ }^{6}$ Residente em Bacterioses dos Animais Domésticos, Departamento de Medicina Veterinária, UFRPE, Recife, PE.
} 
RESUMO.- Objetivou-se com este estudo avaliar a sensibilidade in vitro de Staphylococcus spp. frente a alguns desinfetantes comerciais utilizados no pré e pós-dipping em vacas leiteiras. Foram testados um total de 60 isolados de Staphylococcus spp. identificados como S. aureus (50) e Staphylococcus coagulase positiva (10) recuperados de glândulas mamárias de vacas com mastite subclínica procedentes das regiões Metropolitana do Recife, Agreste e Zona da Mata do Estado de Pernambuco. O estudo da eficácia dos desinfetantes utilizados no pré e pós-dipping foi realizado utilizando-se os seguintes princípios ativos: cloro $(2,5 \%)$, iodo $(0,57 \%)$, clorexidine $(2,0 \%)$, amônia quaternária $(4,0 \%)$ e ácido lático $(2,0 \%)$ em quatro tempos distintos (15", 30", 60" e 300"). Observou-se que $100 \%$ de S. aureus foram sensíveis ao iodo, $93,3 \%$ sensíveis a clorexidine, $80 \%$ sensíveis a amônia, 35,6\% sensíveis ao ácido lático e 97,8\% resistentes ao cloro no tempo de 60". Com relação a Staphylococcus coagulase positiva (SCP), $100 \%$ dos isolados foram sensíveis ao iodo, $81,8 \%$ sensíveis a amônia quaternária, 99,9\% sensíveis ao ácido lático, $72,7 \%$ sensíveis a clorexidine e $100 \%$ resistentes ao cloro no tempo de $60 "$ ". Conclui-se que a maior atividade desinfetante in vitro foi verificada para o iodo e clorexidine frente a $S$. aureus e do iodo e ácido lático frente aos SCP e que há necessidade de avaliação periódica dos desinfetantes utilizados nas propriedades leiteiras nas regiões estudadas, pois, existem variações no perfil de sensibilidade e resistência aos desinfetantes que podem comprometer os programas de controle da mastite bovina causada por Staphylococcus spp.

TERMOS DE INDEXAÇÃO: Desinfetantes, mastite, Staphylococcus spp., vacas leiteiras.

\section{INTRODUÇÃO}

A desinfecção é um dos mais importantes aspectos de prevenção de enfermidades e neste contexto muitos desinfetantes foram desenvolvidos especificamente para a prevenção das doenças na indústria leiteira (Boddie et al. 1997).

Os programas de controle da mastite bovina incluem diferentes estratégias para reduzir a prevalência em níveis economicamente aceitáveis uma vez que a erradicação desta enfermidade não se mostra como uma meta viável (National Mastitis Council 1978, Costa 1991).

A infecção da glândula mamária dos bovinos pode ser controlada com a utilização de substâncias germicidas nos tetos antes e após a ordenha, antibioticoterapia no período de secagem, eliminação dos casos crônicos, tratamento dos casos clínicos durante a lactação e o adequado funcionamento dos equipamentos de ordenha (Philpot \& Nickerson 1992).

Desta forma, a utilização de soluções antissépticas tende a controlar e até mesmo diminuir os riscos de novas infecções da glândula mamária. Entretanto, os desinfetantes podem apresentar pouca eficiência quando na presença de matéria orgânica, sujidades ou urina, dificul- tando desta forma a atuação eficaz do produto (Pankey et al. 1984, Quinn 1991).

Os princípios ativos mais utilizados para desinfecção dos tetos são o iodo, clorexidina, ácido sulfônico, cloro, peróxidos, lauricidina e ácido cloroso. Com objetivo de minimizar a irritação e condicionar a pele dos tetos, são utilizadas algumas bases e emolientes na formulação desses germicidas, como a glicerina, lanolina, propilenoglicol, sorbitol, óleos vegetais, minerais e colágeno (Santos \& Fonseca 2006).

Costa et al. (1998) destacaram a importância do uso adequado dos desinfetantes no controle das mastites uma vez que a presença de matéria orgânica determinou acentuada redução na eficiência dos mesmos.

Vários trabalhos demonstraram a eficiência dos desinfetantes na redução dos casos de mastite subclínica quando utilizados de maneira adequada (Goldberg et al 1994, Freitas 1998, Jones 1998, Brito 2000).

Diversas medidas sanitárias devem ser adotadas durante o processo de ordenha para minimizar a transmissão de agentes causadores de mastites que podem ser transferidos ao leite depreciando sua qualidade microbiológica. Destacam-se a ordenhadeira, a mão do ordenhador e lesões nos tetos considerados fatores importantes que expõem a superfície dos tetos aos microrganismos (Amaral et al. 2004). A higienização prévia dos tetos previne doenças como a mastite sendo de grande importância para reduzir o número de microrganismos patogênicos no leite e melhorar as condições higiênicas do mesmo (Nader Filho et al. 1982).

Considerando a importância da correta escolha do produto desinfetante para o uso na desinfecção dos tetos, realizou-se o presente trabalho com objetivo de determinar a eficácia dos princípios ativos: iodo, cloro, clorexidine, amônia quaternária e ácido lático utilizados no pré e pósdipping para controle das mastites bovinas causadas por Staphylococcus spp. em propriedades leiteiras nas regiões Metropolitana do Recife, Agreste e Zona da Mata do Estado de Pernambuco.

\section{MATERIAL E MÉTODOS}

Foram estudados 60 isolados de Staphylococcus spp. recuperados de leite de vacas com mastite subclínica procedentes de 15 propriedades de exploração leiteira situadas em 13 municípios distribuídos na Região Metropolitana do Recife (2), Agreste (8) e Zona da Mata (3) do Estado de Pernambuco. Os rebanhos eram constituídos de animais de várias raças, idades e encontravam-se em diferentes estágios de lactação, criados em sistema intensivo ou semi-intensivo, com sistemas de ordenhas mecânica ou manual.

As amostras de leite foram colhidas após prévia lavagem do teto com água e sabão, secagem com papel toalha e anti-sepsia do óstio do teto com álcool a $70^{\circ} \mathrm{GL}$. Coletaram-se $5 \mathrm{~mL}$ de leite, em frascos com tampa rosqueável, esterilizados e previamente identificados com o nome ou número do animal e quarto mamário, sendo devidamente enviados, em caixas isotérmicas contendo gelo reciclável, ao Laboratório de Doenças Infecto-Contagiosas da Universidade Federal Rural de Pernambuco. 
No laboratório, alíquotas de leite foram semeadas em placas de Petri contendo ágar base enriquecido com $5 \%$ de sangue de ovino e incubadas em estufa bacteriológica a $37^{\circ} \mathrm{C}$, realizando-se leituras após 24 e $48 \mathrm{~h}$, sendo observadas as características morfológicas das colônias como tamanho, tipo, coloração e presença de hemólise. Ao microscópio, foram observadas a disposição das células e características morfotintorias à técnica de Gram (Carter 1988).

Para a identificação dos isolados de Staphylococcus spp. foram realizadas provas bioquímicas como produção de coagulase livre, DNase e catalase, segundo Silva et al. (1997). As provas de produção de acetoína, fermentação da glicose (anaerobiose) e do manitol (aerobiose e anaerobiose) foram realizadas de acordo com Mc Faddin (1980).

Após a realização dos testes, os isolados foram classificados em Staphylococcus aureus, quando positivo em todos os testes, Staphylococcus coagulase positiva (SCP), quando positivo para a produção da coagulase, fermentação da glicose em anaerobiose e catalase, mas negativa em algum dos outros testes (Baird-Parker 1990).

A determinação da eficácia dos desinfetantes utilizados no pré e pós-dipping foi realizado utilizando-se os seguintes princípios ativos: iodo na concentração de $(0,6 \%)$, ácido lático $(2,0 \%)$, clorexidine $(2,0 \%)$, cloro $(2,5 \%)$ e amônia quaternária $(4,0 \%)$, sendo as diluições realizadas conforme orientação dos fabricantes.

Para a análise foram preparadas suspensões bacterianas homogêneas em solução salina estéril correspondendo ao tubo 1 da escala de McFarland.

A suspensão foi constituída pela solução desinfetante $(0,8 \mathrm{~mL})$ diluída de acordo com o fabricante e o leite estéril $(0,2 \mathrm{~mL})$. Posteriormente, adicionou-se a suspensão bacteriana $(1,2 \mathrm{~mL})$ e cronometrou-se os tempos (15", 30", 60" e 300") de exposição para então realizar o repique em caldo Brain Heart Infusion (BHI).

A mistura foi incubada a $37^{\circ} \mathrm{C}$ durante 24 horas para observação da turvação do meio, formação de película na superfície ou de precipitado no fundo dos tubos. Após a incubação, a suspensão foi repicada em meio sólido (ágar sangue) para confirmação da presença ou ausência do microrganismo testado frente aos diferentes anti-sépticos e tempo de exposição. A ausência do crescimento bacteriano nas placas indicou a eficácia do produto em questão (Costa et al 1998).

A análise estatística empregada foi do tipo descritivo, calculando-se as freqüências absoluta e relativa (Sampaio 1998).

\section{RESULTADOS E DISCUSSÃO}

Nas Figuras 1 e 2 encontram-se os resultados do perfil de sensibilidade e resistência dos Staphylococcus aureus e Staphylococcus coagulase positiva frente as soluções de desinfetantes utilizadas para o pré e pós-dipping.

O perfil de sensibilidade de $S$. aureus frente ao iodo nos tempos de 15", 30", 60" e 300" foi de 93,90\%, 97,80\%, $100,00 \%$ e $100,00 \%$, respectivamente. Quanto ao cloro, observou-se que apenas $2,20 \%, 2,20 \%, 2,20 \%$ e $6,70 \%$ foram sensíveis nos diferentes tempos estudados. Já para a amônia quaternária, os isolados apresentaram $55,60 \%$, $80,00 \%, 80,00 \%$ e $82,20 \%$ de sensibilidade. Com relação ao ácido lático, observou-se que 15,60\%, 17,80\%, 35,60\%

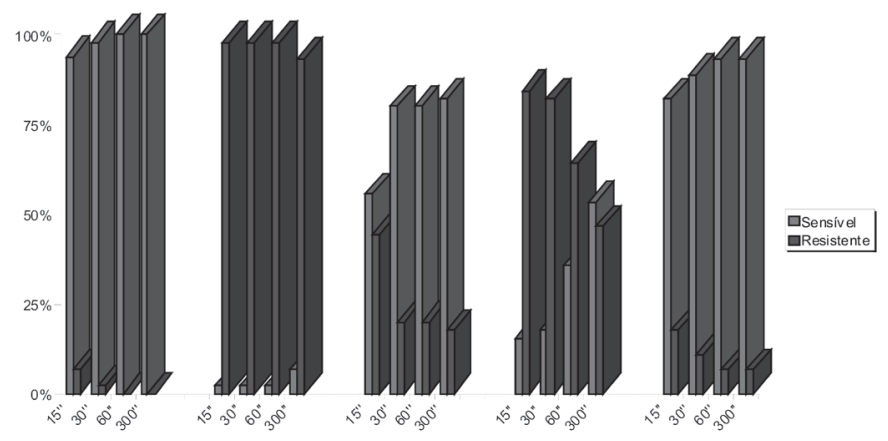

Fig.1. Eficácia in vitro dos desinfetantes utilizados no pré e pósdipping em propriedades leiteiras frente a Staphylococcus aureus isolados na Região Metropolitana do Recife, Agreste e Zona da Mata, Estado de Pernambuco, 2007.

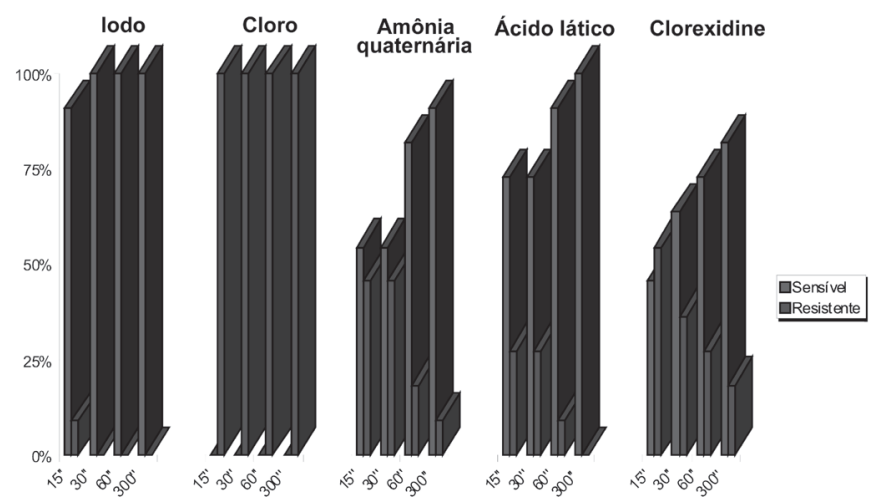

Fig.2. Eficácia in vitro dos desinfetantes utilizados no pré e pósdipping em propriedades leiteiras frente a Staphylococcus coagulase positiva isolados na Região Metropolitana do Recife, Agreste e Zona da Mata, Estado de Pernambuco, 2007.

e $53,30 \%$ dos isolados foram sensíveis. Ainda com relação ao clorexidine, observou-se que $82,20 \%, 88,90 \%$, $93,30 \%$ e $93,30 \%$ dos isolados foram sensíveis nos tempos estudados.

O perfil de sensibilidade dos SCP frente ao iodo nos tempos de 15", 30", 60" e 300" foi de 90,9\%, 100,0\%, $100,0 \%$ e 100,0\%, respectivamente. Quanto ao cloro, observou-se que $100,0 \%$ dos isolados foram resistentes em todos os tempos estudados. Já para a amônia quaternária, os isolados apresentaram $54,5 \%, 54,5 \%, 81,8 \%$ e $90,9 \%$ de sensibilidade. Com relação ao ácido lático, observouse que $72,7 \%, 72,7 \%, 90,9 \%$ e $100,0 \%$ das amostras foram sensíveis. Ainda com relação ao clorexidine, observou-se que $45,5 \%, 63,6 \%, 72,7 \%$ e $81,8 \%$ dos isolados foram sensíveis nos tempos estudados.

Os resultados obtidos neste estudo indicaram maior atividade desinfetante in vitro do iodo e da clorexidine para os $S$. aureus e iodo e ácido lático para os SCP.

Resultados semelhantes foram obtidos por Pedrini \& Margatho (2003) que analisaram microrganismos causadores de mastites contagiosa e ambiental. Eles observaram que as soluções de iodo a $2 \%$ e a $1 \%$ apresentaram melhor desempenho contra todos os microrganismos testados, destacando-se também a ação da clorexidina que 
apresentou bons resultados in vitro. Jones (1998) relatou que soluções de iodo devem ser utilizadas em imersão dos tetos em baixas concentrações ( $0,5 \%$ ou menos), uma vez que soluções a $1 \%$ de iodo podem deixar resíduos no leite.

Os resultados deste estudo também revelaram que a ação do iodo, ácido lático e clorexidine foram maiores quanto maior o tempo de exposição. O clorexidine é bastante utilizado para o tratamento de infecções superficiais de tetos em vacas devido ao seu efeito cumulativo e contínuo, permanecendo na pele no mínimo por seis horas (Spinosa et al. 2002), além disso, atua na presença de matéria orgânica, é de fácil aplicação e econômico. De acordo com Phillips et al. (1991) quando comparado ao iodo, o clorexidine causa menor reação tecidual nas diluições recomendadas.

Os resultados obtidos para o desinfetante a base de cloro foram insatisfatórios, pois quase todas as bactérias estudadas mostraram-se resistentes nos diferentes tempos de análise. Pedrini \& Margatho (2003) relataram que o hipoclorito de sódio a $2 \%$ apresentou excelente eficácia contra todos os microrganismos testados, contudo essa concentração é extremamente irritante para a pele do animal. Constataram ainda que o hipoclorito de sódio a $0,5 \%$, concentração recomendada para rotina, teve efeito antimicrobiano bastante reduzido, corroborando com os achados deste estudo.

De acordo com Amaral et al (2004) o uso do cloro como agente desinfetante é prática comum nas propriedades leiteiras do Brasil, uma vez que o produto apresenta baixo custo. Entretanto, tem como desvantagem sua menor estabilidade, além da não observação das recomendações e critérios de uso pelos produtores. Neste estudo, observou-se que $100,0 \%$ das amostras analisadas foram resistentes a este princípio ativo, sendo desaconselhada sua utilização nas práticas de pré e pós-dipping nas propriedades das regiões estudadas.

Costa et al. (1998) também realizaram estudo sobre a atividade do cloro frente a amostras de Staphylococcus spp., constataram resistência in vitro frente a este desinfetante e ressaltaram a importância do uso adequado uma vez que a presença de matéria orgânica determinou uma diminuição acentuada na eficiência do mesmo.

Ainda de acordo com Amaral et al (2004), o cloro utilizado na desinfecção das teteiras, demonstrou que o produto não foi eficiente na redução dos microrganismos presentes e atribuíram esse resultado a adesão das bactérias à superfície interna das teteiras que dificulta a ação do desinfetante. A concentração e o tempo de contato são fatores que podem interferir na ação do desinfetante (Bessems 1998) e este binômio é fundamental para o sucesso do efeito desinfetante de compostos a base de cloro.

De acordo com Fonseca \& Santos (2000) os melhores resultados no pós-dipping têm sido obtidos com as seguintes concentrações de compostos: iodo $0,7-1,0 \%$, clorexidina $0,5-1,0 \%$ e cloro $0,3-0,5 \%$ (4\% hipoclorito de sódio). No pré-dipping, os produtos tradicionalmente utilizados são: hipoclorito de sódio a $2 \%$, iodo a $0,3 \%$ e clorexidina a $0,3 \%$. Em ambos os casos deve-se fazer a imersão completa dos tetos em solução desinfetante (Santos \& Fonseca 2006).

Pedrini \& Margatho (2003) relataram que na maioria das propriedades estudadas os desinfetantes são escoIhidos por hábito de uso, facilidade de aplicação ou preço. Estes dados corroboram com os obtidos nesse trabaIho, pois a maioria das propriedades visitadas utilizava o produto comercial de fácil aplicação e mais barato. Esses fatores aliados ao fato de nenhuma das propriedades visitadas realizarem testes laboratoriais para avaliar a eficiência das soluções desinfetantes utilizadas na rotina do processo de ordenha podem comprometer a eficácia desses produtos nas regiões estudadas.

Os resultados obtidos por Costa et al. (1998) indicaram a importância da avaliação periódica dos desinfetantes utilizados nas propriedades, pois muitos não se mostraram eficazes para controlar os microrganismos mais prevalentes, tornando, desta forma, o gasto com o produto supérfluo, pois o mesmo já não atua de forma eficiente para os microrganismos testados.

\section{CONCLUSÕES}

De acordo com os resultados obtidos, a maior atividade desinfetante in vitro foi verificada para o iodo e clorexidine frente ao Staphylococcus aureus e do iodo e ácido lático para os Staphylococcus coagulase positiva.

É necessária a avaliação periódica dos desinfetantes utilizados nas propriedades leiteiras das regiões estudadas, pois existem variações no perfil de sensibilidade e resistência que podem comprometer os programas de controle da mastite bovina causada por Staphylococcus spp.

\section{REFERÊNCIAS}

Amaral L.A, Romano A.P.M., Nader Filho A. \& Rossi Jr O.D. 2004. Avaliação da eficiência da desinfecção de teteiras e dos tetos no processo de ordenha mecânica de vacas. Pesq. Vet. Bras. 24(4):173177.

Baird-Parker A.C. 1990. The Staphylococci: an introduction. J. Appl. Bacteriol. 19:15-85.

Bessems E. 1998. The effect of pratical condition on the efficacy of desinfectants. Int. Biodeter. Biodegr. 41(3/4):177-183.

Boddie R.L., Nickerson S.C. \& Adkinson R.W. 1997. Efficacies of teat germicides containing $0.5 \%$ chlorhexidine and $1 \%$ iodine during experimental challenge with Staphylococcus aureus and Streptococcus agalactiae J. Dairy Sci. 80:2809-2814.

Brito J.R.F. 2000. Contagem bacteriana de superfície de tetas de higienização, incluindo a ordenha manual com participação do bezerro para estimular a descida do leite. Ciência Rural, Santa Maria, 30(5):15-19.

Carter G.R. 1988. Fundamentos de bacteriologia e micologia veterinária. Roca, São Paulo. 250p.

Costa E.O. 1991.Importância econômica da mastite infecciosa bovina. Com. Cient. Fac. Med. Vet. Zootec., Univ. São Paulo, 15(1):21-26.

Costa E.O., Ribeiro A.R., Watanabe E.T., Garino Jr F., Silva J.A.B. \& Thiers F.O. 1998. Avaliação in vitro dos desinfetantes utilizados na pós ordenha (teat dipping) para controle da mastite bovina Revta Napgama 1(1):18-22. 
Fonseca L.F.L. \& Santos M.V. 2000. Qualidade do Leite e Controle de Mastite. Lemos Editorial, São Paulo. 175p.

Freitas M.A.Q.1998. Mastite bovina: importância e controle. Circ. Téc. 11, Pesagro-Rio, Niterói. 14p.

Goldberg J.J., Murdough P.A., Howard A.B. \& Drechsler P.A. 1994. Evaluation of a 1 percent iodophor postmilking teat sanitizer. J. Dairy Sci. 77(33):740-747.

Jones G.M. 1998. Milking practices recommended to assure milk quality and prevent mastitis. Dairy Science, Virginia Cooperative Extension, p.404-227.

McFaddin J.F. 1980. Biochemical test for identification of medical bacteria. William and Wilkins, Baltimore. 527p.

Nader Filho A., Schocken-Iturrino R.P., Ávila F.A. \& Montanholi R.A. 1982. Efeito de várias medidas higiênico-sanitárias durante a ordenha na contagem microbiana do leite. Revta Inst. Laticínios Cândido Tostes 37:13-15.

National Mastitis Council 1978. Current Concepts of Bovine Mastitis. 2nd ed. Washington.

Pankey J.W.W.R.J., Eberhart A.L., Cuming R.D., Daggett R.J, Farnsworth \& Mcduff C.K. 1984. Update on postmilking teat antisepsis. J. Dairy Sci. 67:1336.
Pedrini S.C.B. \& Margatho L.F.F. 2003. Sensibilidade de microrganismos patogênicos isolados de casos de mastite clínica em bovinos frente a diferentes tipos de desinfetantes. Arq. Inst. Biológico, São Paulo, 70(4):391-395.

Phillips M.F., Vasseur P.B. \& Gregory C.R. 1991. Clorhexedine diacetate versus povidone-iodine for preoperative preparation of the skin: a prospective randomized comparison in dogs and cats. J. Am. Anim. Hosp. Assoc. 27:105-108.

Philpot W.N. \& Nickerson S.C. 1992. Mastitis: Counter attack. Babson Bros. Co., Naperville, IL. 259p.

Quinn P.J. 1991. Disinfection and disease prevention in veterinary medicine, p.169-175. In: __ (Ed.), Disinfection, Sterilization, and Preservation. 4th ed. Lea and Febiger, Philadelphia.

Sampaio I.B.M. 1998. Estatística Aplicada à Experimentação Animal. UFMG, Belo Horizonte. 221p.

Santos M.V. \& Fonseca L.F.L. 2006. Estratégias para Controle de Mastite e Melhoria da Qualidade do Leite. Editora Manole, Barueri. 314p.

Silva N., Junqueira V.C.A. \& Silveira N.F.A. 1997. Manual de Métodos de Análise Microbiológica de Alimentos. Varela, São Paulo. 295p.

Spinosa H.S., Gorniak S.L. \& Bernadini M.M. 2002. Farmacologia Aplicada à Medicina Veterinária. Guanabara Koogan, Rio de Janeiro. 489p. 